Research Article

\title{
Damage Constitutive Model and Mechanical Performance Deterioration of Concrete under Sulfate Environment
}

\author{
Peng Liu $\mathbb{D}^{1,2}$ Ying Chen ${ }^{10},{ }^{1,2,3}$ Zhiwu Yu, ${ }^{1,2}$ and Zhaohui Lu ${ }^{1,4}$ \\ ${ }^{1}$ School of Civil Engineering, Central South University, 22 Shaoshan Road, Changsha 410075, China \\ ${ }^{2}$ National Engineering Laboratory for High Speed Railway Construction, 22 Shaoshan Road, Changsha 410075, China \\ ${ }^{3}$ School of Civil Engineering, Central South University of Forestry and Technology, 498 Shaoshan Road, Changsha 410004, China \\ ${ }^{4}$ Key Laboratory of Urban Security and Disaster Engineering of Ministry of Education, Beijing University of Technology, \\ Beijing 100124, China
}

Correspondence should be addressed to Ying Chen; cheny83@csu.edu.cn

Received 23 July 2019; Revised 21 February 2020; Accepted 6 March 2020; Published 30 March 2020

Academic Editor: Gisella Tomasini

Copyright $\odot 2020$ Peng Liu et al. This is an open access article distributed under the Creative Commons Attribution License, which permits unrestricted use, distribution, and reproduction in any medium, provided the original work is properly cited.

\begin{abstract}
The effects of erosion mode, erosion age, and concentration of sulfate solution on mechanical properties of concrete were investigated. The dimensionless relationship model of the stress-strain of concrete on the basis of randomness was proposed. The variation of the elasticity modulus and Poisson's ratio of the concrete surface attacked by sulfate was studied, and a novel method of using a superficial parameter to characterize the performance change of the concrete surface was recommended. The results showed that the dimensionless relationship model of stress-strain of concrete could be used to represent the variations of mechanical properties of concrete. The differences of load-displacement of concrete before and after sulfate attack were reflected as the change of curve's slope and ultimate bearing capacity, and the slope of a straight section of the lateral and longitudinal strain curves of concrete surface also varied. The increment rates of ultimate bearing capacity of concrete attacked by $1 \%$ and saturated sulfate solution were about $30 \%$ and $10 \%$, respectively. However, the decreasing ratio of the ultimate bearing capacity of concrete attacked by saturated sulfate solution was approximately $25 \%$. The damage factor of the elasticity modulus of the concrete surface of C20 and C40 was 0.185 and -0.19 , respectively. The obtained results could provide a support for investigating the variations of stress-strain relationship and mechanical performance of concrete under a sulfate environment.
\end{abstract}

\section{Introduction}

The durability and service life of concrete structures can be significantly affected by the environment. Especially, the sulfate attack is a major threat to the durability of concrete structures, which causes strength loss [1], changes of mass [2] and microstructure [3], degradation of durability [4] and service life [5], deformation behavior [6], formations of expansive products [7] and noncohesive mass [8], and loss of cohesion of cement hydration products $[9,10]$. As a consequence, the reliability of the concrete structures is degraded gradually [11]. Stress-strain constitutive relationship is one of the basic mechanical properties of concrete materials, and the stress-strain relationship of concrete subjected to salt corrosion has changed significantly. Therefore, it is very significant to carry out research on the deformation and mechanical property of concrete attacked by sulfate.

Many research studies have been carried out to investigate the mechanism [12-15], deformation, and mechanical properties of concrete [16], modulus variation [17], influence factors [18], external load [19], erosion form [20], and so on. For example, Gong et al. [21] presented the stressstrain relation of concrete under the coupled effects of sustained loading, sulfate attack, and dry-wet cycle, and they proposed a calculation method for the stress-strain relation of concrete under the action of sulfate attack and dry-wet cycle. Zhou et al. [22] presented a study of mechanical performance of FRP-confined sulfate-attacked concrete columns and established the stress-strain relationship of the FRP-confined sulfate-corroded concrete. Nie and Qian [23] 
investigated the whole stress-strain curve of concrete attacked by sulfate and sulfate-chloride compound, and the stress-strain relationship, constitutive parameters, value of character points, and a series of mechanical parameters were studied. Yang et al. [24] studied the uniaxial compressive stress-strain constitutive relation of corroded concrete in a saline soil area of Western China and proposed a constitutive model based on ion diffusion, chemical reaction, and mechanical analysis. Yin et al. [25] simulated the time-dependent mechanical behaviors, such as stress redistribution and bearing capacity degradation of concrete suffering the coupled axial loading and sulfate attack, and a coupled chemomechanical damage constitutive model was determined by introducing the chemical damage. Zhang and She [17] described the modulus variation of a mortar exposed to external sulfate attack, and they pointed out that the elastic modulus values of the mortar attacked by sulfate decreased due to the nucleation of microcracks.

Although a lot of research studies of sulfate attack of concrete have been conducted, only few studies on the relationship of deformation property and stress-strain of concrete attacked by sulfate are found [26, 27]. Especially, the performance evolution law of the concrete surface has not been investigated thoroughly. The objective of this study was to investigate the effects of erosion mode, erosion age, and concentration of sulfate solution on mechanical properties of concrete. A novel dimensionless relationship model of stress-strain of concrete on the basis of randomness was proposed. The change law of the elasticity modulus and Poisson's ratio of the concrete surface attacked by sulfate was studied, and a novel method of using the superficial parameter to characterize the performance change of the concrete surface was recommended. Moreover, the load displacement, dynamic strain, damage factor, and elasticity modulus of concrete were also discussed. The above research can provide a support to understand the constitutive evolution of concrete structures under a sulfate environment, which makes up for weakness of overseas in this field.

\section{Theoretical Analysis}

The microstructure and composition of concrete attacked by sulfate gradually change with time, as do the corresponding properties of concrete [28]. In order to reveal the evolution law of concrete's performance in the sulfate environment, the mechanical properties and deformation of concrete before and after sulfate attack were investigated, respectively.

\subsection{Dimensionless Relationship Model of the Stress-Strain} Curve of Concrete. The stress-strain curve of concrete can be used to characterize the relationship between stress and strain of concrete, which can also represent the elastic plastic deformation and failure characteristics of concrete under the action of external loading. In general, the stress-strain curve of concrete consists of two parts: ascent and descent stages. The load capacity and change characteristics of concrete mostly present at the ascent stage of the stress-strain curve, so the objective was to investigate the effect of sulfate attack on the ascent stage of the concrete stress-strain curve. At present, the most classic stress-strain curve of concrete is the GUO model [29], written as equation (1). Meanwhile, the CEB-FIP model is also recommended by [30], formulated as equation (2):

$$
\begin{aligned}
& y= \begin{cases}\alpha x+(3-2 \alpha) x^{2}+(\alpha-2) x^{3}, & 0 \leq x<1 ; \\
\frac{x}{\beta(x-1)^{2}+x}, & x \geq 1,\end{cases} \\
& y= \begin{cases}\frac{a x-x^{2}}{1+(a-2) x}, & 0 \leq x<1 ; \\
b e^{-\left((x-1)^{2} / 2 c^{2}\right)}+(1-b) e^{-\left((x-1)^{2} / 2 d^{2}\right)}, & x \geq 1,\end{cases}
\end{aligned}
$$

where $x$ is the dimensionless strain of concrete $\left(\varepsilon / \varepsilon_{c}\right)$ and $y$ is the dimensionless stress of concrete $\left(\sigma / \sigma_{c}\right) . a, b, c$, and $d$ are the fitted parameters.

There exist macroscopical deformation and microscopic damage of concrete under the action of external loading, so the nonlinearity of the stress-strain curve of concrete is enhanced. Based on energy principle, the energy dissipation caused by the damage of concrete during the compressive process can be represented as

$$
\begin{aligned}
\int_{0}^{\varepsilon} \sigma(z) \mathrm{d} z & =W_{e}(\varepsilon)-W_{D}(\varepsilon), \\
W_{e}(\varepsilon) & =\frac{E \varepsilon^{2}}{2}, \\
W_{D}(\varepsilon) & =\int_{0}^{\varepsilon} E z D(z) \mathrm{d} z,
\end{aligned}
$$

where $W_{e}(\varepsilon)$ is the strain energy density of concrete with a strain of $\varepsilon . W_{D}(\varepsilon)$ is the released energy density of concrete caused by fracture with a strain of $\varepsilon$. $E$ is the initial elasticity modulus of concrete. $\sigma(z)$ is an external loading, $\varepsilon$ is a macroscopic strain, and $D(z)$ is the damage of concrete caused by external strain of $z$.

To derivate the strain of concrete in equation (3), the stress-strain relation of the concrete under uniaxial compression can be established as

$$
\sigma(\varepsilon)=E \varepsilon(1-D(\varepsilon))
$$

where $D(\varepsilon)$ is the damage of concrete caused by external strain of $\varepsilon$.

Taking into account the randomness of the damage and elasticity modulus of concrete, equation (6) also stands for the stochastic damage constitutive model of concrete under uniaxial compression. Assuming the damage and elasticity modulus of concrete are random variables, and the corresponding mean and variances are $\mu_{D}, V_{D}, \mu_{E}$, and $V_{E}$, respectively. Therefore, the stress of concrete is also a random variable. The corresponding mean and variance of stressstrain of concrete can be written as 


$$
\begin{aligned}
\mu_{\sigma}(\varepsilon) & =\mu_{E} \varepsilon\left(1-\mu_{D}(\varepsilon)\right) \\
V_{\sigma}^{2}(\varepsilon) & =\varepsilon^{2}\left[\left(\mu_{E}^{2}+V_{E}^{2}\right) V_{D}^{2}(\varepsilon)+V_{E}^{2}\left(1-\mu_{D}(\varepsilon)\right)^{2}\right] .
\end{aligned}
$$

Assuming the ultimate compressive strain of concrete is a random variable and follows a specific distribution, so the damage variable $D(\varepsilon)$ is also a random variable obeying certain distribution. Reference [31] proposes that the ultimate compressive strain of concrete obeys the lognormal distribution, and the corresponding probability density function can be represented as equation (8). Therefore, the mean value of damage of concrete under some strain can be formulated as equation (9):

$$
\begin{gathered}
f(x)=\frac{1}{\sqrt{2 \pi} \zeta x} \exp \left[-\frac{(\ln x-\lambda)^{2}}{2 \zeta^{2}}\right] \\
\mu_{D}(x)=\int_{0}^{\varepsilon} \frac{1}{\sqrt{2 \pi} \zeta x} \exp \left[-\frac{(\ln x-\lambda)^{2}}{2 \zeta^{2}}\right] \mathrm{d} x=\Phi\left(\frac{\ln x-\lambda}{\zeta}\right),
\end{gathered}
$$

where $\lambda$ is a mean value of compressive strain of concrete, $\lambda=E(\ln x) . \zeta$ is a standard deviation of compressive strain of concrete, $\zeta=\sqrt{D(\ln x)}$. $\Phi(\cdot)$ stands for a standard normal distribution function.

To simplify the computation process, the mean value of damage in equation (6) is directly adopted. Substitution of equation (9) into equation (6), the corresponding strain of concrete is derivated, written as equation (10). Integrating equations (6), (9), and (10), the compressive peak stress of concrete can be formulated as equation (11):

$$
\begin{aligned}
\frac{\mathrm{d} \sigma(\varepsilon)}{\mathrm{d} \varepsilon} & =E(1-D(\varepsilon))-\frac{E}{\sqrt{2 \pi} \zeta} \exp \left(-\frac{(\ln \varepsilon-\lambda)^{2}}{2 \zeta^{2}}\right), \\
\sigma_{p} & =E \varepsilon_{p}\left(1-D\left(\varepsilon_{p}\right)\right)=E \varepsilon_{p}\left(1-\Phi\left(\frac{\ln \varepsilon_{p}-\lambda}{\zeta}\right)\right),
\end{aligned}
$$

where $\sigma_{p}$ and $\varepsilon_{p}$ are the compressive peak stress and strain of concrete, respectively. as

Setting $\mu_{p}=\left(\left(\ln \varepsilon_{p}-\lambda\right) / \zeta\right)$, equation (11) can be written

$$
\begin{gathered}
D\left(\varepsilon_{p}\right)=1-\eta=\Phi\left(\varepsilon_{p}\right), \\
\mu_{p}=\Phi^{-1}(1-\eta), \\
\zeta=\frac{\exp \left(-0.5 \mu_{p}^{2}\right)}{\sqrt{2 \pi} \eta}, \\
\lambda=\ln \varepsilon_{p}-\zeta \mu_{p},
\end{gathered}
$$

where $E_{p}$ is the secant elasticity modulus of the peak point of the stress-strain curve of concrete and $E_{p}=\left(\sigma_{p} / \varepsilon_{p}\right) . \eta$ is a ratio between the tangent elasticity modulus of the origin point and the secant elasticity modulus of the peak point of the stress-strain curve of concrete, $\eta=\left(E_{p} / E\right)$.

Setting $x=\left(\varepsilon / \varepsilon_{p}\right)$ and $y=\left(\sigma(\varepsilon) / \sigma_{p}\right)$, the dimensionless relationship model of stress-strain of concrete on the basis of equation (6) can be determined:

$$
y=\frac{1-D\left(x \varepsilon_{p}\right)}{\eta} x=\frac{1-\Phi\left(\left(\sqrt{2 \pi} \eta \ln x / \exp \left(-0.5\left(\Phi^{-1}(1-\eta)\right)^{2}\right)\right)+\Phi^{-1}(1-\eta)\right)}{\eta} x
$$

Equation (13) is the dimensionless relationship model of stress-strain of concrete, and it is defined as the DSS model. This model only relates with the change of $\eta$. Therefore, the change law of the mechanical property of concrete attacked by sulfate can be investigated on the basis of the stress-strain curve of concrete before and after sulfate attack.

2.2. Mechanical Property and Deformation. The elasticity modulus and Poisson's ratio are the important elastic parameters to represent the characteristics of concrete. The elasticity modulus of concrete can be used to reflect the resistance of deformability of concrete, and Poisson's ratio embodies the lateral deformation capacity of concrete. GB/T 50081-2002 Standard for Test Method of Mechanical Properties on Ordinary Concrete recommends a method to determine the elasticity modulus of concrete [32]:

$$
E_{c}=\frac{F_{a}-F_{0}}{A} \times \frac{L}{\varepsilon_{b}-\varepsilon_{0}},
$$

where $E_{c}$ is the elasticity modulus of concrete, $L$ is the gauge length, $A$ is the cross-section area of concrete specimen, $F_{0}$ is the initial load with a recommended value of $0.5 \mathrm{MPa}, F_{a}$ is the test load corresponding to the $1 / 3$ axial ultimate compressive strength, and $\varepsilon_{0}$ and $\varepsilon_{b}$ are the measured strains of the concrete specimen under the actions of $F_{0}$ and $F_{a}$ for $60 \mathrm{~s}$, respectively.

The sulfate attack induces a degradation of microstructure and composition of concrete, so there exists a remarkable change of the elasticity modulus and Poisson's ratio of the concrete surface. The elasticity modulus and Poisson's ratio of concrete are the bulk phase parameters, which are used to characterize the entire performance of the concrete specimen. However, the sulfate attack of concrete occurs from the surface to interior, so the performance deterioration mainly takes place at the surface region of concrete. In order to reveal the performance change law of the concrete surface attacked by sulfate, the strain of the concrete surface can be measured by pasting strain gage on the concrete surface. Therefore, the elasticity modulus and 
Poisson's ratio of concrete surface can be calculated from equations (15) and (16), respectively:

$$
\begin{aligned}
& E_{s}=\frac{\sigma_{s}}{\varepsilon_{s}}, \\
& v_{s}=\left|\frac{\varepsilon_{s c}}{\varepsilon_{s a}}\right|,
\end{aligned}
$$

where $E_{s}$ is the elasticity modulus of the concrete surface during the elastic deformation stage of concrete. $\sigma_{s}$ and $\varepsilon_{s}$ are the stress and strain of the concrete surface, respectively. $\nu_{s}$ is Poisson's ratio of the concrete surface. $\varepsilon_{s a}$ and $\varepsilon_{s c}$ are the longitudinal and transverse strains of the concrete surface, respectively.

In order to reveal the change law of stress-strain of the concrete surface, the corresponding curves can be measured by pasting strain gage on the concrete surface. During the test process, a constant loading rate is adopted, that is, $5 \mathrm{kN} /$ s. Therefore, there exists a definite relationship between load and test time, formulated as equation (17). Assuming the external load belongs to distributed load and the crosssection area of the concrete specimen is a constant, so a relationship between stress of concrete and external load can be established as equation (18). Intergrating equations (15), (17), and (18), the corresponding strain of the concrete surface can be written as equation (19):

$$
\begin{aligned}
& F=v t, \\
& F=\sigma A, \\
& \varepsilon_{s}=\frac{v}{E_{s} A} t,
\end{aligned}
$$

where $F$ is an external load, $v$ is the loading rate, and $t$ is the loading time.

The elasticity modulus and Poisson's ratio of the concrete surface can be determined, when the relationship between the stress and strain of the concrete surface is measured by the dynamic strain indicator during the load process. Integrating equations (6) and (19), the damage factor $D_{s}$ of the elasticity modulus of the concrete surface can be deduced.

The above results of theoretical analysis are all based on the assumption that concrete is a homogeneous and isotropic material before and after sulfate attack. The expansive substances generated by sulfate ions can improve the microstructure and decrease the porosity of concrete, which has a positive effect on the performance of concrete. So, the damage factor $D$ in equation (6) is positive. Conversely, the sulfate attack of concrete has a negative effect, and the corresponding value of $D$ in equation (6) is negative. GB/T 50082-2009 Standard for Test Methods of Long Term Performance and Durability of Ordinary Concrete proposes the strength corrosion resistant coefficient of concrete to characterize the effect of sulfate attack on the performance of concrete [33], written as

$$
K_{f}=\frac{f_{n}}{f_{0}} \times 100 \%,
$$

where $K_{f}$ is the strength corrosion resistant coefficient of concrete, $f_{n}$ is the compressive strength of concrete attacked by sulfate, and $f_{0}$ is compressive strength of concrete cured in the standard condition at the same age with the concrete attacked by sulfate.

\section{Experimental Procedure}

3.1. Raw Materials. Portland cement of PO 32.5, polycarboxylic acid series of superplasticizer, river sand with fineness modulus of 2.9, continuous grading limestone gravel with a grain size of $5 \sim 20 \mathrm{~mm}$, and tap water were used in this study. In addition, the commercial anhydrous sodium sulfate with a purity of $99 \%$ was purchased from local market. The concrete of different strength grades (C20, C30, and C40) was produced in the laboratory, and the concrete mixing ratio was listed in Table 1.

3.2. Experimental Process and Device. According to JTG E30-2005 Test Methods of Cement and Concrete for Highway Engineering [34], the concrete specimens of $100 \mathrm{~mm} \times$ $100 \mathrm{~mm} \times 100 \mathrm{~mm}$ and $100 \mathrm{~mm} \times 100 \mathrm{~mm} \times 300 \mathrm{~mm}$ were fabricated, and there were three specimens for each group. All specimens were demoulded after $24 \mathrm{~h}$ and cured for $28 \mathrm{~d}$ at a temperature of $(20 \pm 1)^{\circ} \mathrm{C}$ and a relative humidity of $(95 \pm 5) \%$.

The experimental process of the complete immersion form of concrete attacked by sulfate was carried out as follows. First, different concentrations of sulfate solution, that is, $1 \%, 5 \%, 10 \%$, and saturated solution, were prepared. The concrete specimens were immersed into sulfate solution. In order to ensure the uniformity of sulfate solution, the distance of concrete specimens was set as no less than $2 \mathrm{~cm}$. Then, the sealed solution box was covered with a plastic film to avoid evaporation of water. Finally, the concrete specimens were taken out from sulfate solution, and the dynamic properties test was carried out when the erosion ages of 2 and 4 months are reached. Moreover, the sulfate solution was changed once a week. The experimental process of sulfate attack of concrete with the partial immersion form was similar to that of the complete immersion form; the difference between them was the placement mode of specimens, that is, a half of the concrete specimen was vertically immersed into sulfate solution and another half part was exposed in air.

The mechanical properties of concrete specimens were tested as follows. First, the strain gage with a gauge length of $10 \mathrm{~cm}$ was pasted on the concrete surface. Then, the external test load with a constant loading rate of $5 \mathrm{kN} / \mathrm{s}$ was applied to the concrete specimen. The compressive strength and stressstrain curves of concrete were measured based on GB/T 50081-2002 Standard for Test Method of Mechanical Properties on Ordinary Concrete. The average value of the measured data of three specimens was used to determine the properties of the concrete specimens.

The integrated measurement and control data acquisition system (IMC) of sixteen channels produced by Integrated Measurement \& Control Co., Germany, was used to 
TABle 1: Concrete composition $\left(\mathrm{kg} \cdot \mathrm{m}^{-3}\right)$.

\begin{tabular}{lccccc}
\hline \multirow{2}{*}{ Strength grade } & \multicolumn{5}{c}{ Item } \\
& Cement & Sand & Gravel & Water & Water reducer \\
\hline C20 & 305 & 831 & 1102 & 158 & 3.5 \\
C30 & 362 & 782 & 1105 & 147 & 3.9 \\
C40 & 410 & 733 & 1108 & 135 & 4.3 \\
\hline
\end{tabular}

measure the dynamic strain of the concrete surface. Figure 1 shows the testing process and equipment. The maximum sampling frequency of each channel was $100 \mathrm{kS} / \mathrm{s}$, and the uncertainty of system measurement was less than $0.1 \%$. There were full, half, and quarter bridges for strain measurement of concrete specimens. The DC excitation voltages of the sensor were $5,10,12,15$, and $24 \mathrm{~V}$.

\section{Results and Discussion}

\subsection{Effects of Concentration of Sulfate Solution and Erosion Form on Load-Displacement Curve of Concrete}

4.1.1. Complete Immersion Form. In order to investigate the effect of sulfate attack on performance and microstructure of concrete, the mechanical property of the concrete prism attacked by sulfate with the complete immersion form was investigated. Taking C20 as an example, the effects of concentration of sulfate solution and erosion age on the load-displacement curve of concrete were studied, as shown in Figure 2.

Compared with the noneroded concrete specimen, that is, $\mathrm{C} 20 \mathrm{~KB}$, the change law of the load-displacement curve of concrete attacked by different concentration of sulfate solution is expressed as the increase in curves' slope and variation of ultimate bearing capacity. In an erosion age of 2 months, the ultimate bearing capacity of concrete first increases and then decreases with the increase in concentration of sulfate solution. The increment rate of ultimate bearing capacity of concrete attacked by $1 \%$ sulfate solution is about $30 \%$. However, the corresponding decreasing ratio of concrete attacked by saturated solution is approximately $10 \%$. With the increase in erosion age (4 months), the ultimate bearing capacity of concrete attacked by low-concentration sulfate solutions (i.e., $1 \%$ and 5\%) slightly increases. Nevertheless, the corresponding decreasing ratio of concrete attacked by saturated solution is approximately $25 \%$. The reason may be that the sulfate ions intrude into concrete and react with hydration products including calcium hydroxide $(\mathrm{CH})$, calcium aluminate hydrate $(\mathrm{CAH})$, calcium silicate hydrate (CSH), and plenty of expanded substances, such as ettringite (AFt) and dehydrate gypsum (DG), are generated $[35,36]$. Some pores and cracks are filled by expansive substances, and the compactness of concrete is enhanced. Therefore, the sulfate attack of concrete has a positive effect on the performance of concrete. The load-displacement curve of C20 attacked by saturated sulfate solution differs from others, which may be the result of too much of expansive substances generated by high concentration of sulfate solution [7]. Once there is no enough space to accommodate all these expansive substances, a larger crystallization pressure and tensile stress will be generated, which results in the damage and microcrack in concrete, as shown in Figure 2(b). Moreover, the effective cross sections of the concrete specimen resisting external load decreases after sulfate attacked, so the displacement curve lengthens under lower load. As seen from Figure 2, there exists a significant difference between the load-displacement curve of concrete attacked by different erosion ages, that is, 2 and 4 months. After eroded for 4 months, the load-displacement curves of concrete attacked by low concentration of sulfate solution become smoother, and the corresponding load-displacement curves of concrete attacked by saturated solution fluctuate greatly.

In addition, the effects of concentration of sulfate solution and erosion age on load-displacement curve of different concrete strength grade, that is, C30 and C40, were also investigated, as shown in Figures 3 and 4.

Compared with noneroded concrete specimens, that is, $\mathrm{C} 30 \mathrm{~KB}$ and $\mathrm{C} 40 \mathrm{~KB}$, the change law of the load-displacement curve of concrete attacked by different concentrations of sulfate solution is expressed as an increase in curves' slope and variation of ultimate bearing capacity. After the 2month sulfate attack, the ultimate bearing capacity of the concrete specimen increases. With the increase in erosion age (4 months), although the ultimate bearing capacity of concrete attacked by low-concentration sulfate solutions (i.e., $1 \%, 5 \%$, and $10 \%$ ) increases, the corresponding value of C30 attacked by saturated sulfate solution decreases. However, the ultimate bearing capacity of $\mathrm{C} 40$ attacked by sulfate solution still increases. Sulfate attack has double effects, that is, positive or negative effect, on the macroperformances, composition, and microstructure of concrete, as reported of References $[3,37,38]$. The higher the concentration of sulfate solution, the larger is the concentration gradient of the concrete surface. More and more sulfate ions intrude into concrete and react with hydration products of cement, plenty of expansive substances are formed in the pores and interfacial transition zone $[39,40]$. Therefore, the microstructure and phase composition of concrete attacked by the sulfate change with the increase in erosion age and sulfate solution concentration. The variations of microstructure and composition of concrete attacked by sulfate can be termed as the change of macroproperties of concrete specimens. Compared with $\mathrm{C} 30 \mathrm{~KB}$, the ultimate bearing capacity of C30 attacked by sulfate solution obviously increases. The lower the concentration of sulfate solution, the more is the increase in the ultimate bearing capacity. However, the ultimate bearing capacity of C30 attacked by different concentration of sulfate solutions, that is, $1 \%, 5 \%$, and $10 \%$, tends to be the same value after 4 months. Compared with $\mathrm{C} 30$, the ultimate bearing capacity of C40 attacked by sulfate solution slightly changes. The higher the concrete strength grade, the more compact the microstructure and less sulfate ions can intrude into the concrete interior. Therefore, a few of expansive substances have a positive effect on concrete. At a low concentration of sulfate solution, the ultimate bearing capacity of concrete increases with the increase in erosion age, that is, 4 months. The variation of the ultimate bearing capacity of concrete 


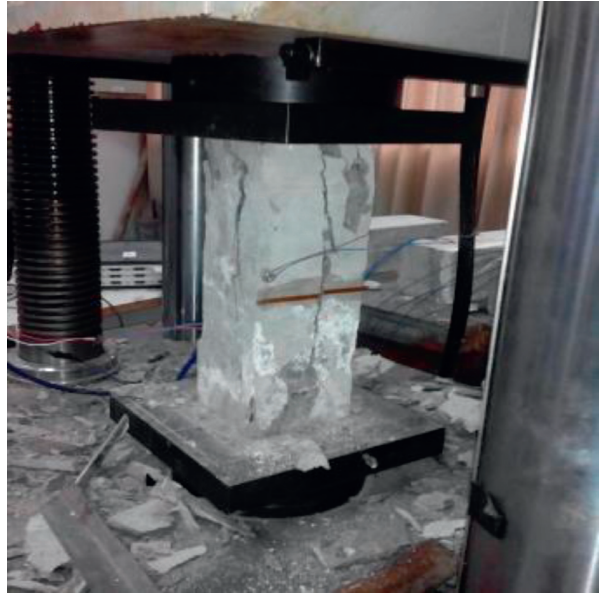

(a)

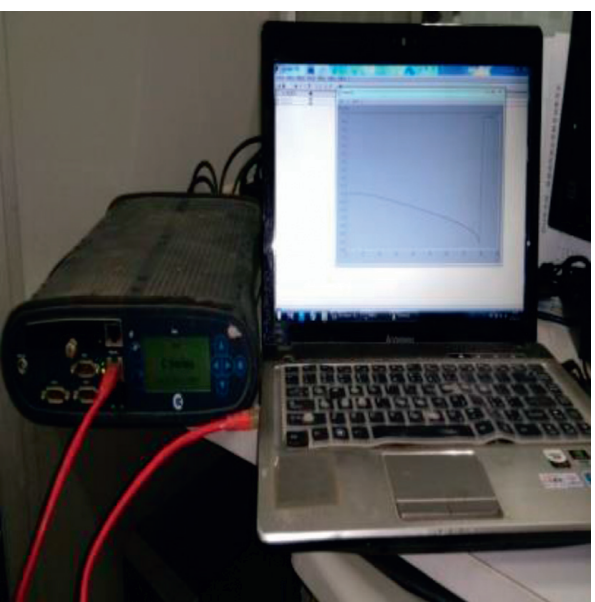

(b)

FIGURE 1: Testing process and equipment. (a) Test of mechanical property of concrete. (b) IMC.

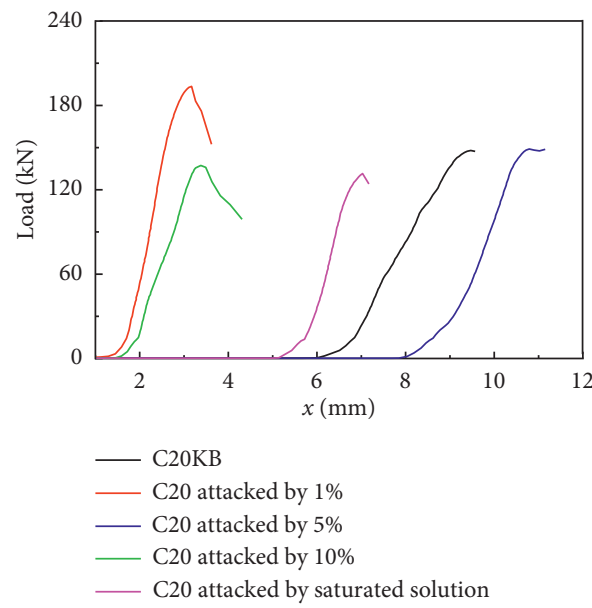

(a)

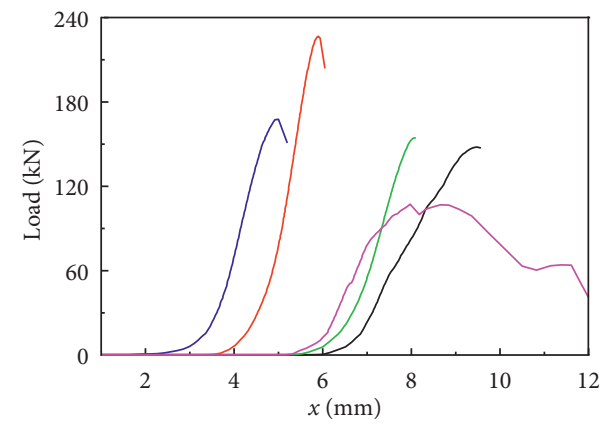

- $\mathrm{C} 20 \mathrm{~KB}$

— C20 attacked by $1 \%$

— C20 attacked by $5 \%$

- C20 attacked by $10 \%$

_ C20 attacked by saturated solution

(b)

FiguRE 2: Effects of concentration of sulfate solution and erosion age on load-displacement curves of concrete. (a) Attacked for 2 months. (b) Attacked for 4 months.

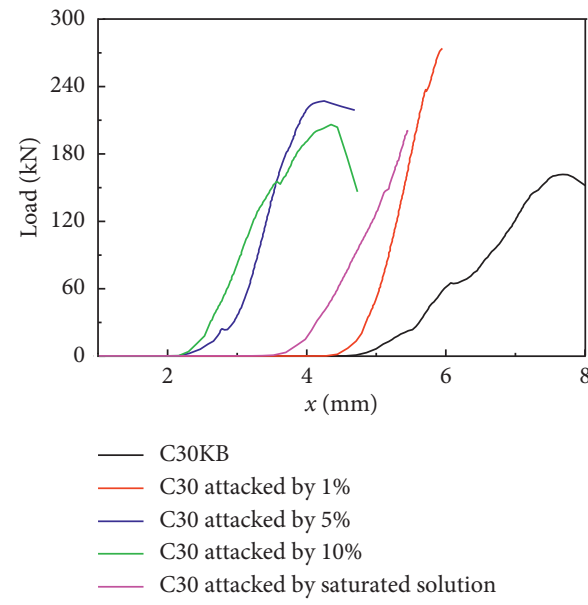

(a)

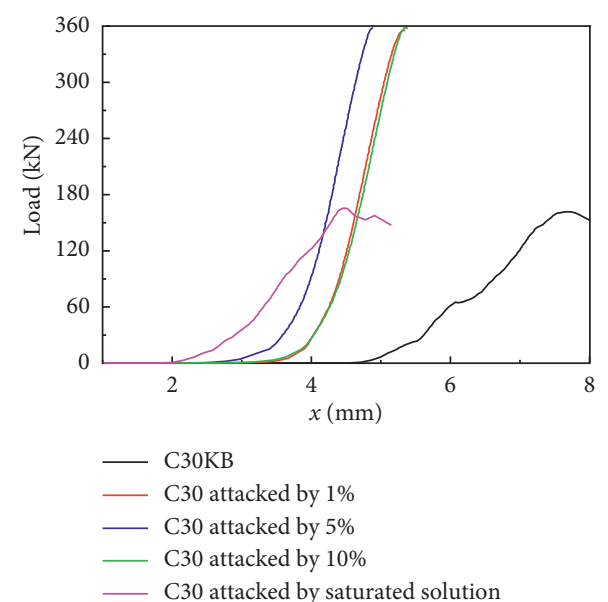

(b)

Figure 3: Effect of concentration of sulfate solution on load-displacement curves of C30. (a) Attacked for 2 months. (b) Attacked for 4 months. 


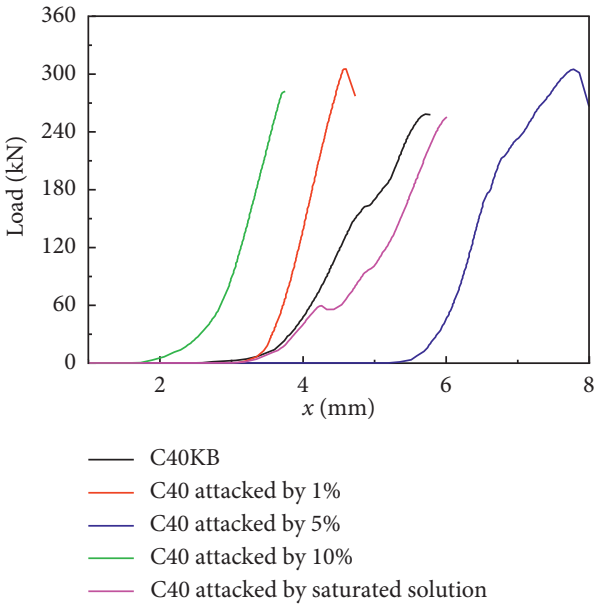

(a)

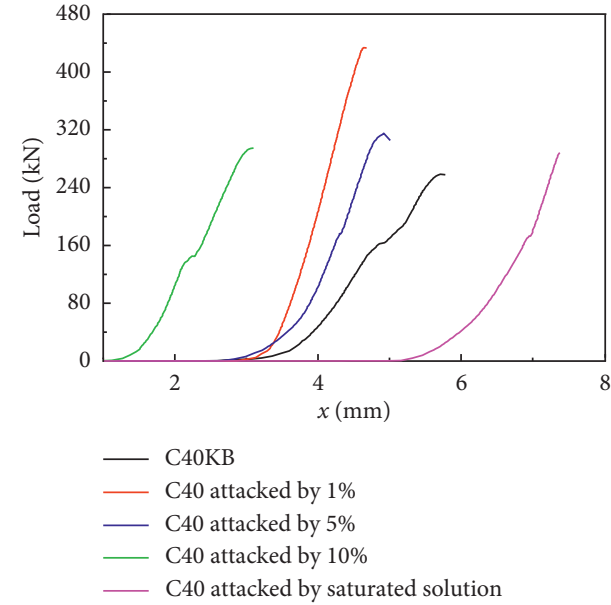

(b)

Figure 4: Effect of concentration of sulfate solution on load-displacement curves of C40. (a) Attacked for 2 months. (b) Attacked for 4 months.

decreases with an increase in the concrete strength grade at the same concentration of sulfate solution. That may be due to the difference of permeability of different concrete strength grade, that is, the higher the strength grade of concrete, the lower the porosity of the microstructure and the less the permeability coefficient. Moreover, the generated substances also fill the pores and decrease the number of ion transmission channels, which enhances the sulfate resistance of concrete. Therefore, the microstructure and characteristics play an important role on sulfate resistance of concrete.

4.1.2. Partial Immersion Form. The effect of the partial immersion form on load-displacement of concrete attacked by sulfate for 4 months was also investigated. The $10 \%$ solution and the saturated solution defined as B10 and BB, respectively, were used in this study. Figure 5 shows the effect of concentration of sulfate solution on load-displacement of concrete before and after sulfate attack.

Compared with noneroded concrete specimen, that is, $\mathrm{C} 20 \mathrm{~KB}$, the slopes of load-displacement curves and the ultimate bearing capacity of C20 attacked by sulfate decrease. However, the change laws of C30 and C40 are just opposite to that of $\mathrm{C} 20$. The ultimate bearing capacity of concrete attacked by saturated solution decreases obviously compared with that attacked by the solution of $10 \%$, which also first decreases and then increases with the increase in the concrete strength grade under the same concentration of sulfate solution. That is caused by the positive and negative double effects of sulfate attack on concrete. The porosity of C20 is large, so more sulfate ions can intrude into concrete through the interconnected pores and generate more expansive substances. Once there is no enough space for them, a larger crystallization pressure and damage will be generated. On the macrolevel, it is expressed as the decrease in curves' slope and ultimate bearing capacity. The higher the concrete strength grade, the less the porosity of concrete. So the concrete possesses a better resistance to sulfate attack.

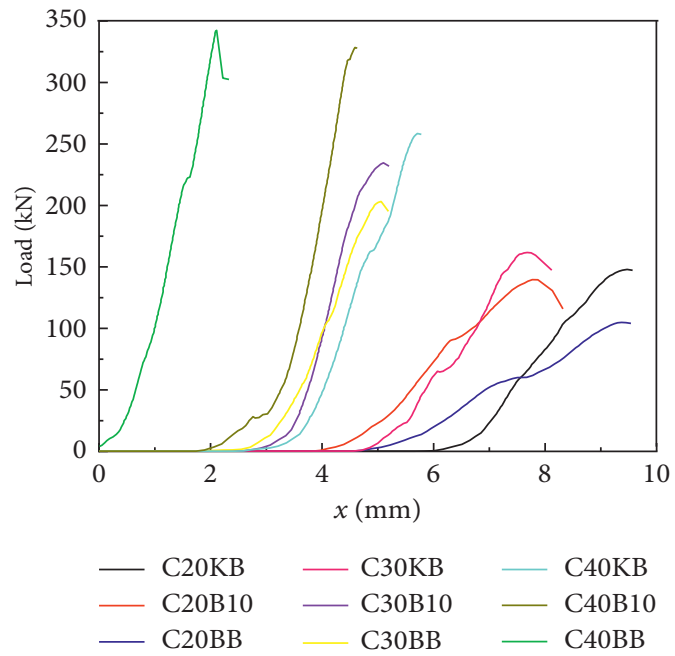

FIGURE 5: Effect of concentration of sulfate solution on load-displacement curves of concrete.

Simultaneously, the expansive substances generated can fill the pores and microcracks in concrete, which has a positive effect on concrete. Compared with the change of concrete attacked by the complete immersion form in Figures 2(b) and 3(b), the ultimate bearing capacity of C20 and C30 attacked by the partial immersion form decreases, however, that of the C40 increases, as shown in Figure 5. That is caused by the difference in the erosion form, that is, a half of the concrete specimen immersed in solution and another half exposed in air. A wetting-drying cycling region on the concrete surface is generated in the area where the solution contacts with air $[41,42]$. The salt crystallization and solution concentration phenomenon occur with water evaporation, which accelerates sulfate attack and generates larger crystallization pressure. There exist microcrack and damage when the crystallization pressure is more than the ultimate tensile strength of concrete. The microstructure of C40 is 
denser, and the sulfate attack also has a positive effect. Therefore, the ultimate bearing capacity of C40 increases. The above results also imply that the erosion form of sulfate attack can also affect the damage of concrete.

\subsection{Effects of Concentration of Sulfate Solution and Erosion} Form on Dynamic Strain of Concrete. Sulfate attack can affect the composition, microstructure, and macro properties of concrete. In order to investigate the variation characteristic of the concrete surface before and after sulfate attack, the dynamic strain of the concrete surface was tested by IMC. There were three specimens for each group, and the typical measured data of one specimen were chosen to present the dynamic property of the specimen. The corresponding results were shown as follows.

4.2.1. Complete Immersion Form. Transverse and longitudinal strains of the concrete surface attacked by sulfate were measured, and the elasticity modulus and Poisson's ratio of the concrete surface were calculated based on the slope of linear elasticity of strains' curve. Taking concrete prisms attacked by saturated sulfate solution for 4 months as an example, the transverse and longitudinal strains of the concrete surface under the action of a loading rate of $5 \mathrm{kN} / \mathrm{s}$ were measured, as shown in Figure 6. Transverse and longitudinal strains of the concrete surface were labeled with $-\mathrm{H}$ and $-\mathrm{S}$, respectively.

In Figure 6, the difference of transverse and longitudinal strains of the concrete surface before and after sulfate attack is mainly the slope change of linear elasticity of strains' curve. There exists a corresponding relationship due to the constant loading ratio of $5 \mathrm{kN} / \mathrm{s}$, written as equation (17). Therefore, there is a linear relationship between the elasticity modulus of the concrete surface and the reciprocal of the slope of linear elasticity of strains' curve, formulated as equation (19). The elasticity modulus of the concrete surface can be determined based on the linear elasticity of strains' curve in Figure 6. Moreover, Poisson's ratio of the concrete surface can also be calculated on the basis of the ratio of transverse and longitudinal strain curves' slope, represented as equation (16). There exists a good relationship between stress and strain within the linear elasticity, so the straight segment ranging from 0.1 to 0.5 was used to determine the slope of the strain curve. The damage change law of the concrete surface can be investigated based on the variation of the mechanical property of concrete before and after sulfate attack. In Figure 6(a), the elasticity modulus and Poisson's ratio of the concrete surface of $\mathrm{C} 20 \mathrm{~KB}$ are $6.5 \mathrm{GPa}$ and 0.19 , respectively. However, those of $\mathrm{C} 20$ attacked by saturated sulfate solution for 4 months are $5.3 \mathrm{GPa}$ and 0.184 , respectively. The reason is that the sulfate attack has a negative effect on the performance of concrete. The above results accord well with the measured ultimate bearing capacity in Figure 2(b). As can be seen from Figure 6(b), the elasticity modulus and Poisson's ratio of the concrete surface of $\mathrm{C} 40 \mathrm{~KB}$ are $10.5 \mathrm{GPa}$ and 0.22 , respectively. Nevertheless, those of $\mathrm{C} 40$ attacked by saturated sulfate solution for 4 months are $12.5 \mathrm{GPa}$ and 0.38 , respectively. That is due to the reason that sulfate attack has a positive effect on the property of concrete. As seen from Figure 6, the elasticity modulus of the $\mathrm{C} 20$ concrete surface attacked by sulfate decreases to 0.815 of the initial value, so the damage factor of the elasticity modulus $D_{s}$ of the concrete surface is 0.185 . However, the elasticity modulus of the C40 concrete surface attacked by sulfate increases to 1.19 of the initial value, so the damage factor of the elasticity modulus $D_{s}$ of the concrete surface is -0.19 . The above results indicate that the sulfate attack has different effects on concrete of different strength grade. The higher the strength grade of concrete, the denser the microstructure of concrete. A little sulfate ions intrude into concrete and generate expansive products which can enhance and improve the compactness of concrete. Conversely, the sulfate attack has a negative effect on concrete of low-strength grade. So, the mechanical property and deformation of low-strength grade of concrete degrade when the sulfate attack has a negative effect on concrete.

In order to investigate the effect of sulfate attack on the mechanical property and deformation of concrete, the influence of concentration of sulfate solution and erosion age on strain of concrete attacked by complete immersion form was studied simultaneously. Figure 7 shows the effect of concentration of sulfate solution and erosion age on strain of the concrete surface.

As can be seen from Figure 7, the difference in transverse and longitudinal strains of the concrete surface attacked by different concentration of sulfate solution and erosion age is characterized as the strain and the slope of linear elasticity of strains' curve. After attacked by sulfate for 2 months, the slope of linear elasticity of strains' curve of C20 first decreases and then increases with the increase in concentration of sulfate solution, which implies that the elasticity modulus of the concrete surface first increases and then decreases with the increase in solution, as shown in Figure 7(a). However, the slope of linear elasticity of strains' curve of C20 attacked by sulfate for 4 months increases with the increase in concentration of sulfate solution, which implies that the elasticity modulus of the concrete surface decreases [22], as shown in Figure $7(\mathrm{~b})$. That is due to the reason that the sulfate attack of concrete has the positive and negative double effects on concrete. The slopes of the linear elasticity of strains' curves of C30 and C40 attacked by sulfate decrease with an increase in the concentration of sulfate solution, which implies that the elasticity modulus of the concrete surface increases. The property difference of different concrete strength grades is the main reason of above results. In addition, the concrete surface erosion inducing eccentric compression results in a great fluctuation of strain curve.

4.2.2. Partial Immersion Form. Taking concrete attacked by sulfate solution for 4 months as an example, the effects of concentration of sulfate solution and partial immersion form on transverse and longitudinal strains of the concrete surface were investigated, as shown in Figure 8.

Compared with the complete immersion form, the partial immersion form of sulfate attack has a different effect on transverse and longitudinal strains of the concrete surface, that is, the strain of the C20 concrete surface fluctuates 


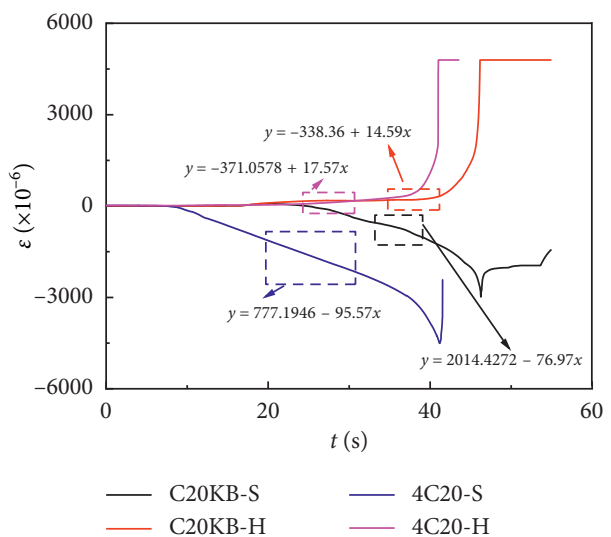

(a)

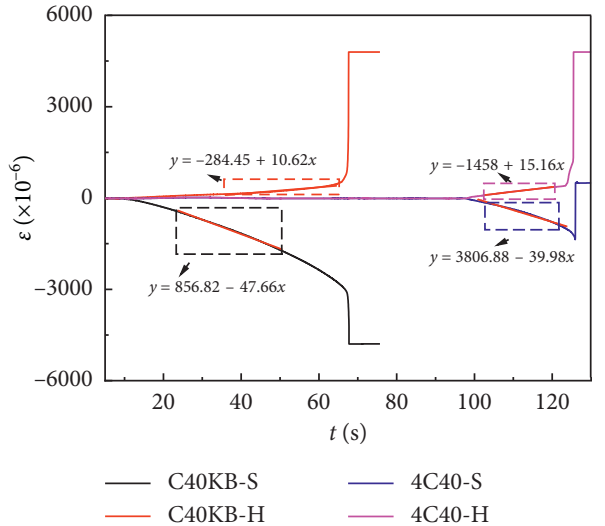

(b)

Figure 6: Transverse and longitudinal strains of the concrete surface before and after sulfate attack. (a) C20. (b) C40.

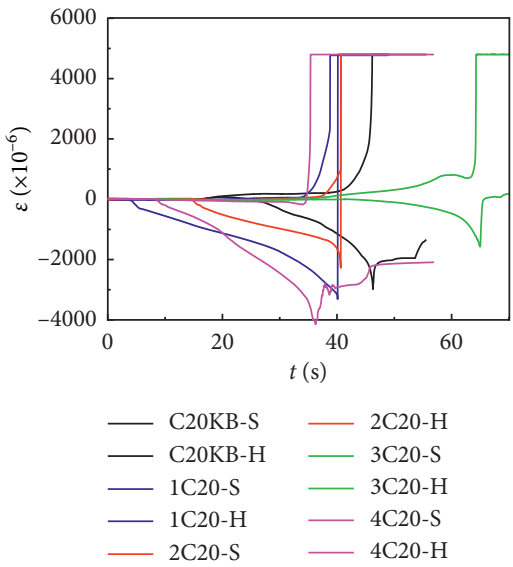

(a)

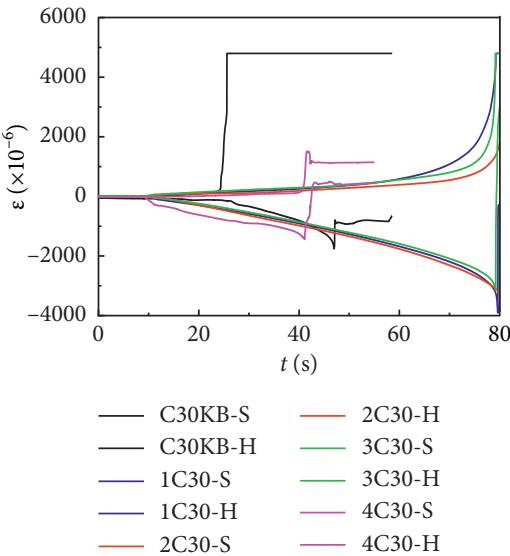

(d)
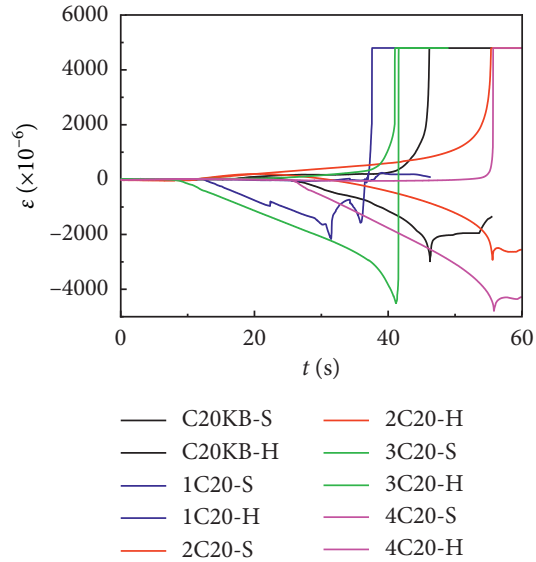

(b)

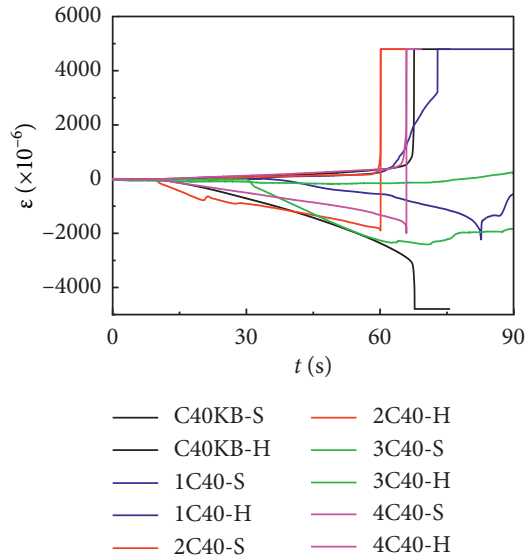

(e)
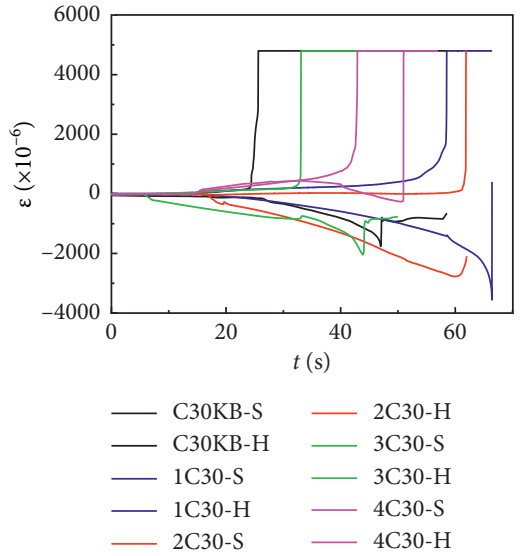

(c)

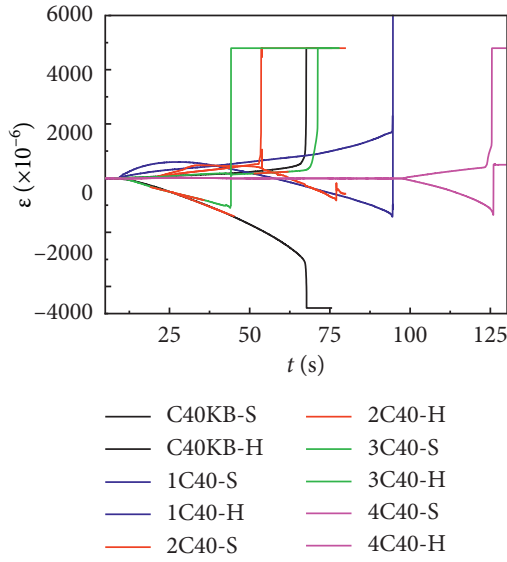

(f)

FIGURE 7: Transverse and longitudinal strains of the concrete surface eroded by complete immersion form. (a) Attacked for 2 months of C20. (b) Attacked for 4 months of C20. (c) Attacked for 2 months of C30. (d) Attacked for 4 months of C30. (e) Attacked for 2 months of C40. (f) Attacked for 4 months of C40.

greatly and the longitudinal strain slightly decreases. The above results are caused by the negative effect of sulfate attack. Moreover, the slope of linear elasticity of strains' curve of C20 first decreases and then increases with the increase in concentration of sulfate solution. The reasons may be due to that more expansive substances and sulfate 


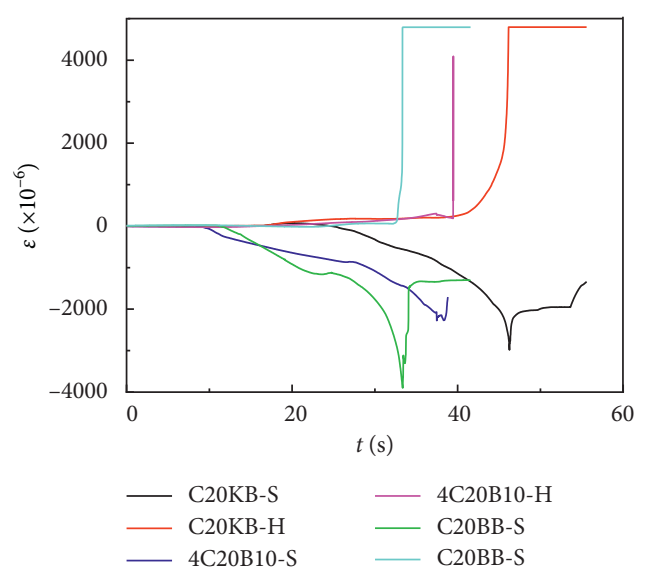

(a)

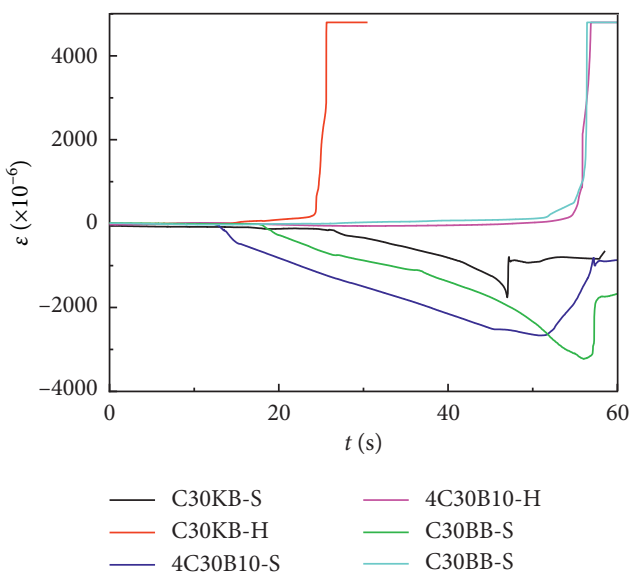

(b)

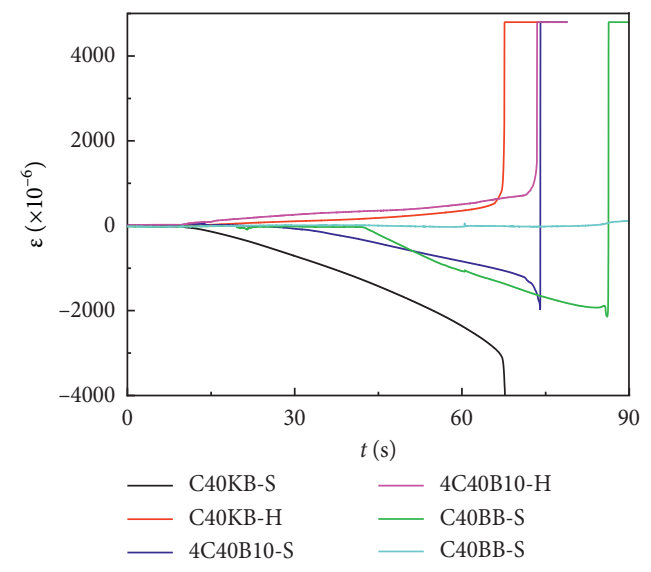

(c)

Figure 8: Transverse and longitudinal strains of the concrete surface eroded by partial immersion form. (a) C20. (b) C30. (c) C40.

salt crystals are generated under the high concentration of sulfate solution, so the crystallization pressure and internal stress in concrete induce the damage of microstructure [38]. The slopes of linear elasticity of strains' curve of C30 and C40 decrease with the increase in concentration of sulfate solution, which implies that the elasticity modulus of the concrete surface attacked by sulfate increases. The higher the strength grade of concrete, the larger the resistance of concrete. Therefore, the sulfate attack has a positive effect on concrete. In addition, there exists a larger fluctuation change of strain curves of the concrete surface, that is, C20BB-S and $\mathrm{C} 30 \mathrm{BB}-\mathrm{S}$. That is due to the reason that the damage of concrete eroded by partial immersion form mainly focuses on the wetting-drying cycling region of the concrete specimen, which results in degradation and cracking of the concrete surface. The above results lead to the internal stress redistribution and eccentric pressured loading.

\subsection{Effect of Sulfate Attack on Mechanical Property and Deformation}

4.3.1. Axial Compressive Strength and Strength Corrosion Resistant Coefficient of Concrete. The effects of concentration of sulfate solution and erosion age on axial compressive strength and the strength corrosion resistant coefficient of concrete eroded by the complete immersion form were investigated, as shown in Figure 9.

In Figure 9, the axial compressive strength and the strength corrosion resistant coefficient of concrete first increase and then decrease with the increase in concentration of sulfate solution, and they also decrease with erosion age. Although the change law of compressive strength and the strength corrosion resistant coefficient of concrete of different strength grade is similar, the variation and percentage change are difference. In addition, the change of the strength corrosion resistant coefficient of concrete becomes more significant with erosion age. The above results accord well with that of References $[38,43]$. Both the strength corrosion resistant coefficient of $\mathrm{C} 20$ and $\mathrm{C} 30$ is less than one with the erosion age of 2 months and the concentration of sulfate solution larger than 5\%. However, the strength corrosion resistant coefficient of $\mathrm{C} 40$ is less than one under the erosion age of 4 months and the concentration of sulfate solution larger than $10 \%$. The sulfate attack of concrete has a positive effect on concrete when the concentration of sulfate solution is at low concentration. Conversely, it has a negative effect on concrete with the increase in sulfate solution. More 


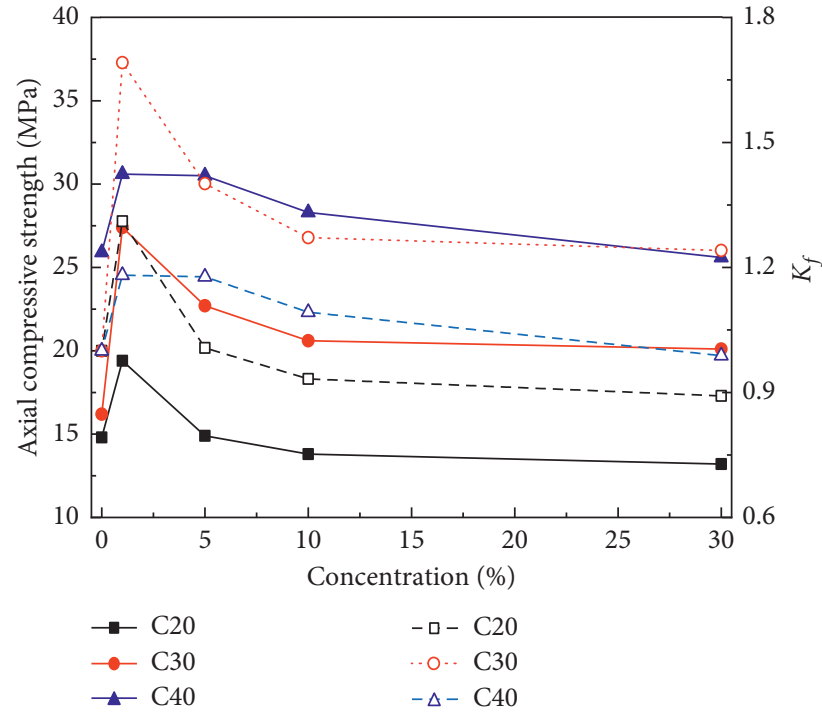

(a)

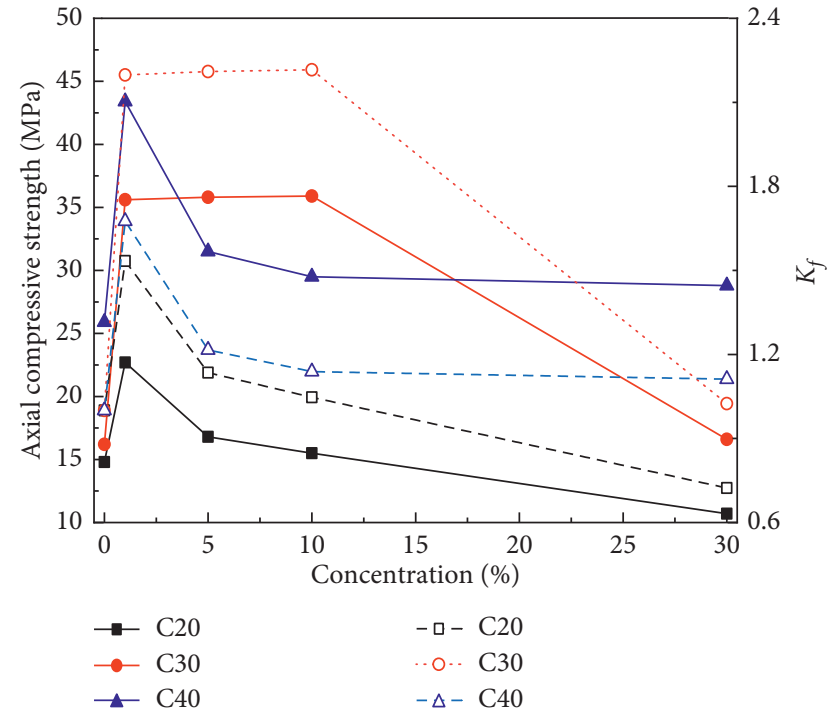

(b)

FiguRE 9: Axial compressive strength and the strength corrosion resistant coefficient of concrete. (a) Attacked for 2 months. (b) Attacked for 4 months.

sulfate ions can intrude into concrete due to more interlocking pore and porosity of low strength grade concrete, so the effect of sulfate attack on concrete of low strength grade is more remarkable. With erosion age, more sulfate ions can intrude into concrete. The axial compressive strength of concrete increases when the sulfate attack has a positive effect, and vice versa.

Taking the concrete attacked for 4 months as an example, the axial compressive strength and strength corrosion resistant coefficient of concrete eroded by partial immersion form were investigated, as shown in Figure 10.

The difference of concrete strength grade has a significant effect on the axial compressive strength and strength corrosion resistant coefficient of concrete eroded by the partial immersion form. The axial compressive strength and strength corrosion resistant coefficient of C20 decrease with the increase in concentration of sulfate solution. However, the corresponding values of C40 increase, and those of C30 first increase and then decrease. The above results may be caused by the property difference of concrete. The higher the strength grade of concrete, the less the number of interlocking pores of concrete, the better the resistance to sulfate attack. Therefore, the sulfate attack can have different effects on property of concrete. Macroscopically, there exist differences in the change law of axial compressive strength and the strength corrosion resistant coefficient. Comparing Figure 9(b) with Figure 10, the change laws of the axial compressive strength and strength corrosion resistant coefficient of concrete eroded by partial and complete immersion forms are different. When the partial immersion form of sulfate attack was adopted, only a half of the concrete specimen was immersed into the sulfate solution, so the salt crystal and solution concentration in the wetting-drying region of concrete have an acceleration effect on degradation of concrete.

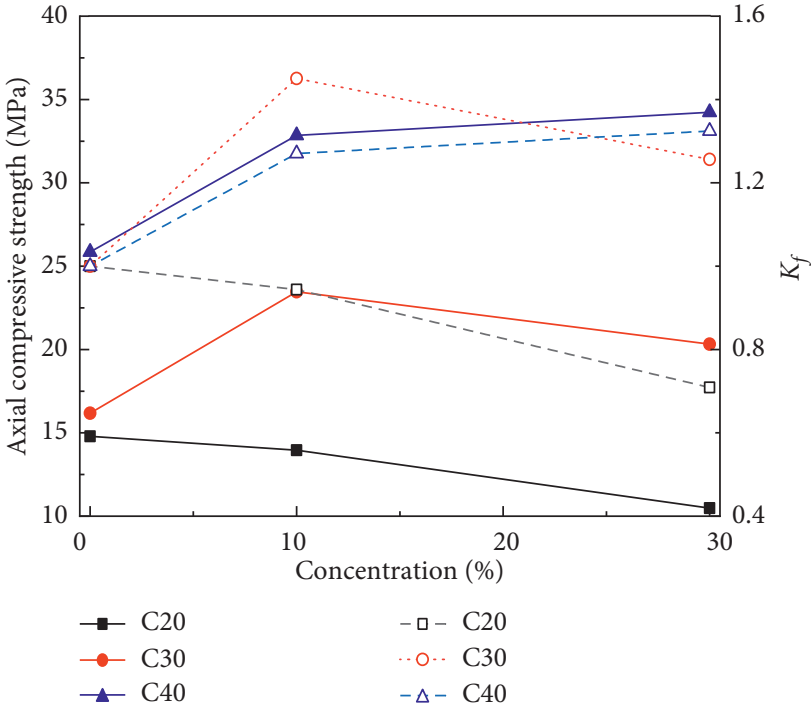

FIgURE 10: Axial compressive strength of concrete eroded by partial immersion form.

4.3.2. Elasticity Modulus and Damage Factor of Concrete. Based on the load-displacement curves of concrete in Section 4.1, the effects of concentration of sulfate solution on the elasticity modulus and damage factor of concrete were studied, as shown in Figure 11. In order to eliminate errors of poor contacting and rough surface, the compressive strength value of $3 \mathrm{MPa}$ was set as an initial value. A part of linear elasticity of strains' curve of concrete, that is, within 0.4 ultimate load, was used to calculate the elasticity modulus of concrete.

Figure 11(a) shows that the elasticity modulus of concrete attacked by sulfate for 2 months first increases and then decreases with the increase in concentration of sulfate 


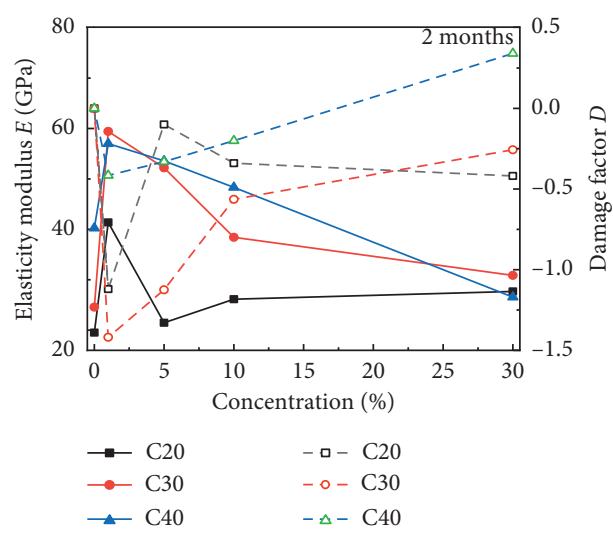

(a)

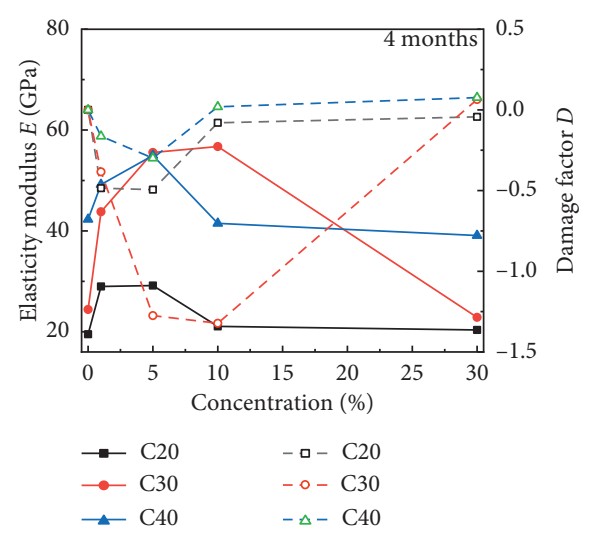

(b)

Figure 11: Effect of concentration of sulfate solution on the elasticity modulus and damage factor of concrete. (a) Attacked for 2 months. (b) Attacked for 4 months.

solution, and its value is larger than that of the noneroded concrete. The lower the concrete strength grade, the more significant the elasticity modulus of concrete. The damage factor of concrete attacked by sulfate first decreases and then increases with the increase in concentration of sulfate solution, which is due to that the sulfate attack has a positive effect on concrete. Therefore, the damage factor of concrete is negative. The larger the concentration gradient of the concrete surface, the more the expansive substances generated. Once there is no enough space to accommodate the expansive substances, the larger crystallization pressure would be generated, which results in the damage of microstructures. The sulfate attack has a negative effect on concrete, so the damage factor of concrete is positive. The elasticity modulus of concrete attacked by sulfate for 4 months first increases and then decreases with the increase in concentration of sulfate solution, but the damage factor of concrete first decreases and then increases. The concentration of sulfate solution corresponding to the maximum elasticity modulus and damage factor of concrete attacked by sulfate for 4 months changes from $1 \%$ to $5 \%$. Comparing Figure 2 with Figure 11, it can be seen that the elasticity modulus and damage factor of $\mathrm{C} 20$ are more significant, and the elasticity modulus of concrete attacked by sulfate decreases with erosion age under the same concentration of solution.

4.3.3. Elasticity Modulus and Poisson's Ratio of Concrete Surface. Based on the results in Section 4.2, the effects of concentration of sulfate solution on elasticity modulus and damage factor of concrete surface were investigated. Simultaneously, the damage factor change law of elasticity modulus of the concrete surface was studied on basis of equation (6). Figure 12 shows the effects of concentration of sulfate solution on the elasticity modulus and damage factor of concrete surface.

The elasticity modulus of the concrete surface first increases and then decreases with the increase in concentration of sulfate solution, but the corresponding damage factor shows a contrary tendency. The lower the strength grade of concrete, the more significant the elasticity modulus and damage factor of the concrete surface. Compared with concrete attacked by sulfate for 2 months, there exists a remarkable difference in the elasticity modulus and damage factor of the concrete surface attacked by sulfate for 4 months. The elasticity modulus of the C20 concrete surface is lower than that of the noneroded specimen, and the corresponding damage factor is positive. However, that of C30 and C40 is larger than the noneroded specimen, and the corresponding damage factor is negative. The expansive substances generated by sulfate attack can fill the pores and improve the microstructure [44], which results in an increase in the resistance of deformation of concrete surface to external load; thus, the elasticity modulus of concrete surface increases. More and more expansive substances generate with the increase in the erosion age and concentration of sulfate solution, which results in damage of microstructure and cracking. Therefore, the elasticity modulus of the concrete surface decreases. Comparing Figure 11 with Figure 12, although the change law of concrete's elasticity modulus is similar to that of the concrete surface, the variation extent is different. The concrete's elasticity modulus is a parameter to reflect the overall performance of the concrete specimen, which is defined as a bulk phase parameter. However, the elasticity modulus of the concrete surface is used to characterize the performance of the concrete surface, which is defined as a superficial parameter. The sulfate attack occurs from the surface to the center, so the concrete surface first degrades [45]. The most important is that the concrete surface is composed of a mortar. Therefore, the elasticity modulus of the concrete surface is less than that of the bulk concrete. The above results also imply that the superficial parameter is only indirectly used to represent the change law of the mechanical property; however, the bulk phase parameter, that is, the elasticity modulus of the concrete surface, can be directly used to characterize the variation of concrete before and after sulfate attack. Therefore, the stress-strain curve of the concrete surface can be employed to describe the change in the 


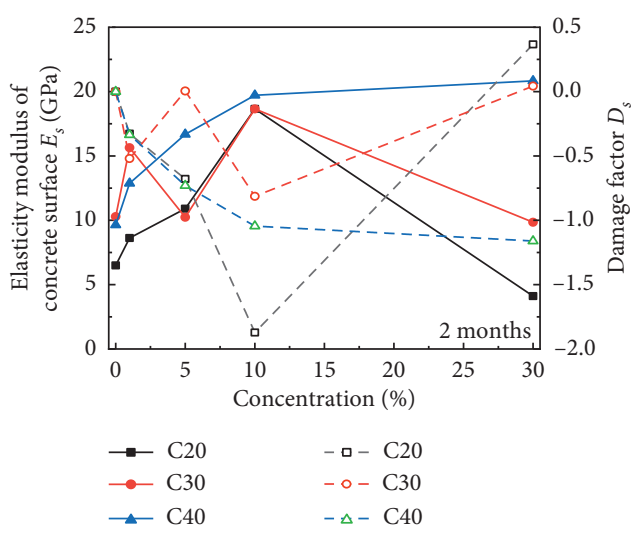

(a)

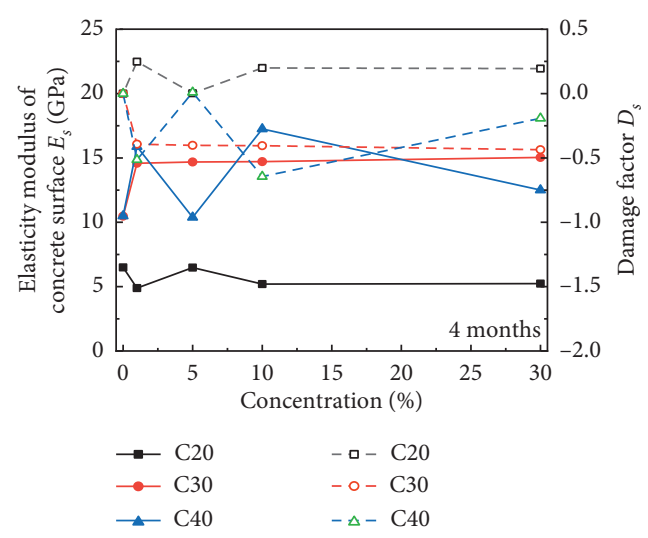

(b)

FIGURE 12: Effect of concentration of sulfate solution on the elasticity modulus and damage factor of the concrete surface. (a) Attacked for 2 months. (b) Attacked for 4 months.

concrete surface. In this study, the effect of concentration of sulfate solution on Poisson's ratio of the concrete surface was also investigated, as shown in Figure 13.

In Figure 13, Poisson's ratio of the concrete surface first increases and then decreases with the increase in concentration of sulfate solution, and the change in Poisson's ratio of the C20 concrete surface is more significant. Poisson's ratio of the concrete surface gradually decreases with erosion age, that is, 4 months. Figure 13 also implies that Poisson's ratio of the C20 concrete surface attacked by sulfate for 2 months is larger than that for 4 months. However, Poisson's ratio of the C30 concrete surface attacked by sulfate for 2 months is larger than that for 4 months when the concentration of sulfate solution is no larger than 5\%. Moreover, Poisson's ratio of the C40 concrete surface attacked by sulfate for 2 months is less than that for 4 months. The increase in Poisson's ratio of the concrete surface indicates the resistance to transverse deformation of the concrete surface increases when the concrete specimen is loaded without plastic deformation. As discussed above, Poisson's ratio of the concrete surface can be used as another superficial parameter to describe the characteristic of the performance change of the concrete surface before and after sulfate attack.

\subsection{Effect of Sulfate Attack on the Dimensionless Relationship} Model of Stress-Strain of Concrete. In order to verify the rationality of the dimensionless relationship model of stressstrain of concrete, that is, equation (13), taking C20 as an example, the effect of concentration of sulfate solution on stress-strain curves of concrete attacked by sulfate for 4 months was investigated. The corresponding calculated results were also compared with the typical stress-strain model of concrete, as shown in Figure 14. In order to eliminate the nonlinear resulted by the errors of poor contacting and rough surface, the compressive strength value of $3 \mathrm{MPa}$ was set as initial value to study the rising parts of the stress-strain curve of concrete before ultimate stress.

The relationship of stress-strain curves of concrete before and after sulfate attack can be characterized by three

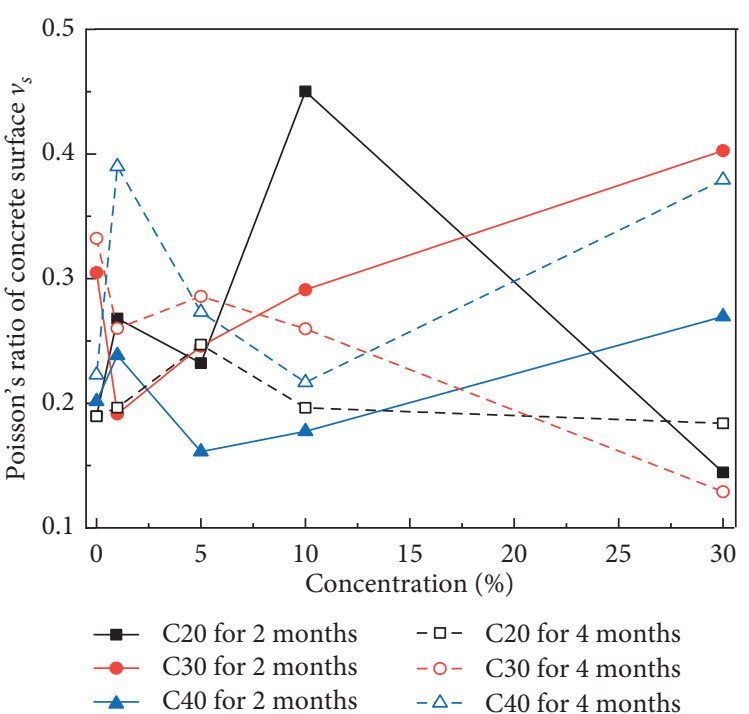

FIGURE 13: Effect of concentration of sulfate solution on Poisson's ratio of the concrete surface.

different models, and the calculated results accord well with the measured data. Among them, the GUO model has the highest accuracy. The dimensionless stress-strain curves of concrete can be divided as two parts based on the demarcation point of a strain ratio of 0.6 . The dimensionless stressstrain curve of concrete increases almost linearly when the strain ratio of curve is less than 0.6. Conversely, it tends to be nonlinear. Compared with $\mathrm{C} 20 \mathrm{~KB}$, the slope of the dimensionless stress-strain curve of concrete attacked by sulfate increases within the strain ratio ranging from 0.2 to 0.6. Simultaneously, the corresponding curve changes linearly. The above results indicate that it is an elastic deformation, and the elasticity modulus of concrete increases. That is due to that the sulfate attack has a positive effect on concrete. The slope of the dimensionless stress-strain curve of concrete attacked by $10 \%$ sulfate solution increases significantly, which is because that more sulfate ions intruding into concrete are generated into expansive substances. 


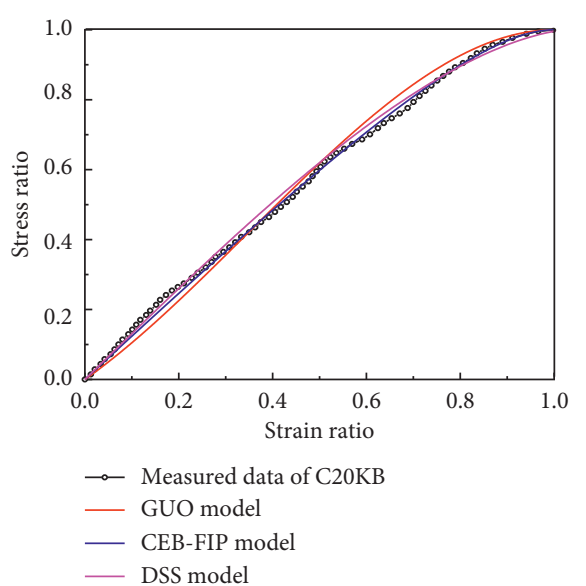

(a)

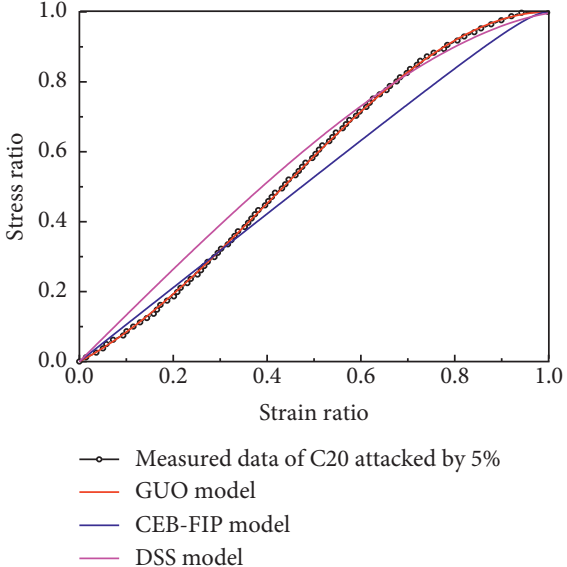

(b)

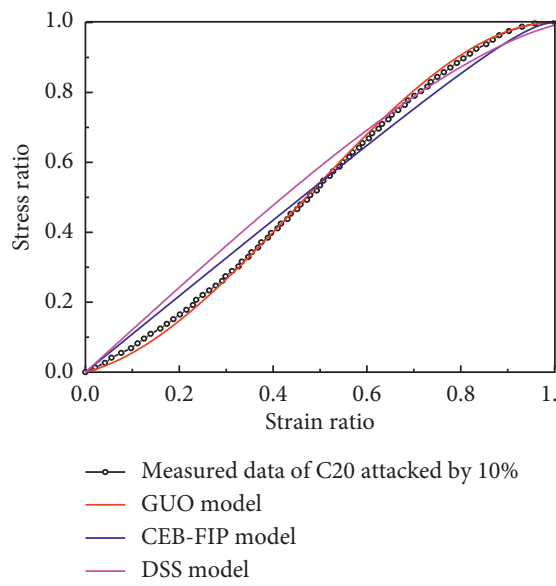

(c)

Figure 14: Effect of sulfate attack on the dimensionless relationship model of stress-strain of concrete. (a) Noneroded sample. (b) Eroded by $5 \%$ sulfate solution. (c) Eroded by $10 \%$ sulfate solution.

Compared with models of GUO and CEB-FIT, the DSS model of the dimensionless relationship model of stressstrain of concrete has an advantage, that is, the randomness of the damage factor of concrete during the compression process can be involved and the corresponding stress-strain curves of concrete with different assurance rates can be determined. Figure 14 also indicates that the change law of dimensionless stress-strain curves of concrete calculated by the models of CEB-FIT is basically the same as that of the DSS.

\section{Conclusions}

(i) The effects of sulfate attack on the load-displacement curve of concrete are mainly expressed as the increase in curve's slope and variation of ultimate bearing capacity. The axial compressive strength and strength corrosion resistant coefficient of concrete first increase and then decrease with the increase in concentration of sulfate solution. The increment rates of ultimate bearing capacity of concrete attacked by $1 \%$ and saturated sulfate solution are about $30 \%$ and $10 \%$, respectively. However, the decreasing ratio of the ultimate bearing capacity of concrete attacked by saturated sulfate solution is approximately $25 \%$. With the increase in the concentration of sulfate solution, there exist differences of axial compressive strength and strength corrosion resistant coefficient of different strength grade of concrete attacked by the partial immersion form.

(ii) The differences of transverse and longitudinal strains of the concrete surface attacked by different concentrations of sulfate solution and erosion age are expressed as the strain and the slope of linear elasticity of strains' curve. The elasticity modulus and Poisson's ratio of C20 attacked by saturated sulfate solution for 4 months are $5.3 \mathrm{GPa}$ and 0.184 , respectively. The damage factor of the elasticity modulus of the concrete surface of C20 and C40 are 0.185 and -0.19 , respectively.

(iii) A dimensionless relationship model of stress-strain of concrete on the basis of randomness is proposed to reveal the change law of the stress-strain curve of 
concrete before and after sulfate attack, and the numerical simulation results accord well with the measured data. On the basis of the demarcation point of a strain ratio of 0.6 , the dimensionless stress-strain curve of concrete is composed of linear part and nonlinear part. The results indicate that the change law of dimensionless stress-strain curves of concrete calculated by the models of CEB-FIT is basically the same as that of the DSS.

\section{Data Availability}

The data used to support the findings of this study are available from the corresponding author upon request.

\section{Conflicts of Interest}

The authors declare that they have no conflicts of interest.

\section{Acknowledgments}

This work was funded by the National Natural Science Foundation of China (grant numbers 51778632, U1434204, U1934217, 51820105014, and 51408614) and China Postdoctoral Science Foundation (grant numbers 2016M600675 and 2017T100647). The authors have received research grants from the Guangdong Provincial Key Laboratory of Durability for Marine Civil Engineering (grant numbers GDDCE14-03, 15-08, 17-02, and 18-16), Basic Research on Science and Technology Program of Shenzhen (JCYJ20170818143541342 and JCYJ20180305123935198), National Engineering Laboratory for High Speed Railway Construction (HSR201903) of China, and Natural Science Foundation of Hunan Province of China (2017JJ3385).

\section{References}

[1] J. Tang, H. Cheng, Q. Zhang, W. Chen, and Q. Li, "Development of properties and microstructure of concrete with coral reef sand under sulphate attack and drying-wetting cycles," Construction and Building Materials, vol. 165, pp. 647-654, 2018.

[2] K. M. Lee, S. H. Bae, J. I. Park, and S. O. Kwon, "Mass change prediction model of concrete subjected to sulfate attack," Mathematical Problems in Engineering, vol. 2015, Article ID 298918, 10 pages, 2015.

[3] M. Vyšvařil, P. Bayer, and M. Rovnaníková, "Microstructural changes of fine grained concrete exposed to a sulfate attack," Materiali in Tehnologije, vol. 49, no. 6, pp. 883-888, 2015.

[4] L. Jiang, D. Niu, L. Yuan, and Q. Fei, "Durability of concrete under sulfate attack exposed to freeze-thaw cycles," Cold Regions Science and Technology, vol. 112, pp. 112-117, 2015.

[5] M. Zhang, L. M. Yang, J. J. Guo, W. L. Liu, and H. L. Chen, "Mechanical properties and service life prediction of modified concrete attacked by sulfate corrosion," Advances in Civil Engineering, vol. 2018, Article ID 8907363, 7 pages, 2018.

[6] D. Sun, K. Wu, H. Shi, S. Miramini, and L. Zhang, "Deformation behaviour of concrete materials under the sulfate attack," Construction and Building Materials, vol. 210, pp. 232-241, 2019.

[7] D. Niu, L. Jiang, and Q. Fei, "Deterioration mechanism of sulfate attack on concrete under freeze-thaw cycles," Journal of Wuhan University of Technology-Materials Science Edition, vol. 28, no. 6, pp. 1172-1176, 2013.

[8] M. M. Rahman and M. T. Bassuoni, "Thaumasite sulfate attack on concrete: mechanisms, influential factors and mitigation," Construction and Building Materials, vol. 73, pp. 652-662, 2014.

[9] T. Ikumi and I. Segura, "Numerical assessment of exterbak sykfate attack in concrete structures. A review," Cement and Concrete Research, vol. 121, pp. 91-105, 2019.

[10] D. Zou, H. Cheng, T. Liu, S. Qin, and T.-H. Yi, "Monitoring of concrete structure damage caused by sulfate attack with the use of embedded piezoelectric transducers," Smart Materials and Structures, vol. 28, no. 10, Article ID 105039, 2019.

[11] Y. Tan, H. Yu, H. Ma, Y. Zhang, and C. Wu, "Study on the micro-crack evolution of concrete subjected to stress corrosion and magnesium sulfate," Construction and Building Materials, vol. 141, pp. 453-460, 2017.

[12] S. Zhutovsky and R. D. Hooton, "Experimental study on physical sulfate salt attack," Materials and Structures, vol. 50, no. 1, pp. 1-10, 2017.

[13] P. K. Mehta, "Mechanism of expansion associated with ettringite formation," Cement and Concrete Research, vol. 3, no. 1, pp. 1-6, 1973.

[14] J. Haufe and A. Vollpracht, "Tensile strength of concrete exposed to sulfate attack," Cement and Concrete Research, vol. 116, pp. 81-88, 2019.

[15] M. F. Najjar, M. L. Nehdi, A. M. Soliman, and T. M. Azabi, "Damage mechanisms of two-stage concrete exposed to chemical and physical sulfate attack," Construction and Building Materials, vol. 137, pp. 141-152, 2017.

[16] L. Nie, J. Xu, and E. Bai, "Dynamic stress-strain relationship of concrete subjected to chloride and sulfate attack," Construction and Building Materials, vol. 165, pp. 232-240, 2018.

[17] H. Zhang and W. She, "A modulus variation model of concrete under external sulfate attack: new perspective from statistical evolution of micro cracks," Journal of Wuhan University of Technology-Materials Science Edition, vol. 33, no. 6, pp. 1465-1471, 2018.

[18] M. Yao and J. Li, "Effect of the degradation of concrete friction piles exposed to external sulfate attack on the pile bearing capacity," Ocean Engineering, vol. 173, pp. 599-607, 2019.

[19] S.-f. Chen, M.-l. Zheng, and B.-g. Wand, "Study of highperformance concrete subjected to coupled action from sodium sulfate solution and alternating stresses," Journal of Materials in Civil Engineering, vol. 21, no. 4, pp. 148-153, 2009.

[20] Z. Zhang, X. Jin, and W. Luo, "Long-term behaviors of concrete under low-concentration sulfate attack subjected to natural variation of environmental climate conditions," $\mathrm{Ce}$ ment and Concrete Research, vol. 116, pp. 217-230, 2019.

[21] J. Gong, J. Cao, and Y. F. Wang, "Effect of creep on the stressstrain relation of fly-ash slag concrete in marine environments," Structural Concrete, vol. 20, no. 3, pp. 1076-1085, 2019.

[22] Y. Zhou, M. Li, L. Sui, and F. Xing, "Effect of sulfate attack on the stress-strain relationship of FRP-confined concrete," Construction and Building Materials, vol. 110, pp. 235-250, 2016.

[23] Y. F. Nie and C. X. Qian, "Constitutive relation of sulfate attacked concrete based on uniaxial loading," Advanced Materials Research, vol. 168-170, pp. 50-56, 2011.

[24] D. Yang, C. Yan, S. Liu, J. Zhang, and Z. Hu, "Stress-strain constitutive model of concrete corroded by saline soil under uniaxial compression," Construction and Building Materials, vol. 213, pp. 665-674, 2019. 
[25] G.-J. Yin, X.-B. Zuo, Y.-J. Tang, O. Ayinde, and J.-L. Wang, "Numerical simulation on time-dependent mechanical behavior of concrete under coupled axial loading and sulfate attack," Ocean Engineering, vol. 142, pp. 115-124, 2017.

[26] Q. Liu, D. Liu, Y. Tian, and X. Liu, "Numerical simulation of stress-strain behaviour of cemented paste backfill in triaxial compression," Engineering Geology, vol. 231, pp. 165-175, 2017.

[27] Y. Zhang, S. Dai, W. Weng, J. Huang, Y. Su, and Y. Cai, "Stress-strain relationship and seismic performance of castin-situ phosphogypsum," Journal of Applied Biomaterials \& Functional Materials, vol. 15, no. 1_suppl, pp. 62-68, 2017.

[28] Y. N. Liang, T. Ji, Y. Z. Zhuang, and A. M. Shen, "The effect of flexural stress on sulfate attacked concrete," in Proceedings of the 2011 International Symposium on Innovation and Sustainability of Structures in Civil Engineering, pp. 1333-1337, Xiamen, China, 2011.

[29] Z. H. Guo, Test and Constitution Relationship of Strength and Deformation of Concrete: Experimental Foundation and Constitutive Relations, Tsinghua University Press, Beijing, China, 1997.

[30] Comite Euro-International Du Beton, CEB-FIP Model Code 1990 (Design Code), Thomas Telford Publishing, London, UK, 1993.

[31] Z. H. Lu, "Research on the stochastic damage of constitutive modeling theory and testing of concrete," Thesis, Tongji University, Shanghai, China, 2002.

[32] GB/T 50081-2002, Standard for Test Method of Mechanical Properties on Ordinary Concrete, China Building Industry Press, Beijing, China, 2003.

[33] GB/T 50082-2009, Standard for Test Methods of Long Term Performance and Durability of Ordinary Concrete, China Building Industry Press, Beijing, China, 2009.

[34] JTG E30-2005, Test Methods of Cement and Concrete for Highway Engineering, China Communications Press, Beijing, China, 2005.

[35] L. X. Nie, J. Y. Xu, and E. L. Bai, "The research on static and dynamic mechanical properties of concrete under the environment of sulfate ion and chlorine ion," Computers and Concrete, vol. 20, no. 2, pp. 205-214, 2017.

[36] B. Tian and M. D. Cohen, "Does gypsum formation during sulfate attack on concrete lead to expansion?" Cement and Concrete Research, vol. 30, no. 1, pp. 117-123, 2000.

[37] M. H. Alyami, R. S. Alrashidi, H. Mosavi, M. A. Almarshoud, and K. A. Riding, "Potential accelerated test methods for physical sulfate attack on concrete," Construction and Building Materials, vol. 229, Article ID 116920, 2019.

[38] P. Liu, Y. Chen, Z. Yu, and Z. Lu, "Effect of sulfate solution concentration on the deterioration mechanism and physical properties of concrete," Construction and Building Materials, vol. 227, Article ID 116641, 2019.

[39] H. Zhang, T. Ji, and H. Liu, "Performance evolution of the interfacial transition zone (ITZ) in recycled aggregate concrete under external sulfate attacks and dry-wet cycling," Construction and Building Materials, vol. 229, Article ID 116938, 2019.

[40] S. Gao, J. Jin, G. Hu, and L. Qi, "Experimental investigation of the interface bond properties between SHCC and concrete under sulfate attack," Construction and Building Materials, vol. 217, pp. 651-663, 2019.

[41] Z. Yu, Y. Chen, P. Liu, and W. Wang, "Accelerated simulation of chloride ingress into concrete under drying-wetting alternation condition chloride environment," Construction and Building Materials, vol. 93, pp. 205-213, 2015.
[42] P. Liu, Z. Yu, Z. Lu, Y. Chen, and X. Liu, "Predictive convection zone depth of chloride in concrete under chloride environment," Cement and Concrete Composites, vol. 72, pp. 257-267, 2016.

[43] R. Dhole, M. D. A. Thomas, K. J. Folliard, and T. Drimalas, "Chemical and physical sulfate attack on fly ash concrete mixtures," ACI Materials Journal, vol. 116, no. 4, pp. 31-42, 2019.

[44] H. Haynes, R. O’Neill, M. Neff, and P. K. Mehta, "Salt weathering distress on concrete exposed to sodium sulfate environment," ACI Materials Journal, vol. 105, no. 1, pp. 35-43, 2008.

[45] W.-H. Huang, "Properties of cement-fly ash grout admixed with bentonite, silica fume, or organic fiber," Cement and Concrete Research, vol. 27, no. 3, pp. 395-406, 1997. 